\title{
La Fundación Manuel Benedito: problemática de un museo de autor
}

\section{The Manuel Benedito Foundation: Problems of Musée d'Auteur}

\author{
María Jesús Rodríguez de la EsPeranzA \\ Fundación Manuel Benedito \\ C/Juan Bravo, 4. 28006 Madrid \\ directora@fundacionmanuelbenedito.com
}

Recibido: 8-05-2014

Aceptado: 7-11-2014

\section{RESUMEN}

Se presenta la Fundación Manuel Benedito como ejemplo de museo privado, sin financiación externa, para explicar cómo es la actualidad de este tipo de instituciones ante la crisis económica y cuál es el futuro que se les presume, dando alternativas para su subsistencia.

Palabras clave: Casas-museo. Museos de autor. Museografía. Colección. Divulgación. Financiación.

\begin{abstract}
A look into the Manuel Benedito Foundation, a private museum with no external funding, as a showcase for the reality of self-financed institutions in times of economic downturn, their prospects for the coming years and their alternatives for survival.
\end{abstract}

KeY words: House-museum. Museum of author. Museography. Collection. Cultural dissemination. Funding. 


\section{Vida y obra de Manuel Benedito}

Manuel Benedito Vives nació en Valencia en 1875. Pronto sus padres notaron sus dotes artísticas y le matricularon en la Academia de Bellas Artes de San Carlos (Valencia). A través de las relaciones de su padre se pone en contacto con Sorolla (1893-1895), quien le trae consigo a Madrid como discípulo para seguir trabajando bajo su protección dos años más. En 1897 gana la Tercera Medalla Nacional por "El Aseo después de trabajo" y, en 1899, obtiene el pensionado para la Escuela Española de Bellas Artes en Roma con el cuadro "La familia de anarquista el día de la ejecución". Durante su estancia en Roma, quizás influenciado por otros pensionados como Chicharro y Álvarez de Sotomayor, matiza su paleta y los temas a tratar. Además, valiéndose de sus dotes comunicativas, comienza a vender sus primeras obras, llegando incluso a ofertar alguna de ellas a Víctor Manuel III y al papa León XIII. Los dos últimos años de pensionado se dedicó a viajar por el Norte de Europa, visitando Bretaña, Holanda y Bélgica, donde estudió el retrato del siglo XVII holandés y profundizó en el tratamiento de la luz.

De regreso a España se establece en Madrid, e influido por la Generación del 98 viaja para pin- tar las tierras salmantinas de Candelario y Salvatierra de Tormes (1906 y 1907). Será en 1908 cuando comience su exitosa carrera como retratista con las obras "Cleo de Merode", "Boceto de los hijos de Alfonso XIII", "Pastora Imperio" y "General Weyler". En la documentación consta que mantuvo estudio en París entre 1910 y 1911, donde realiza obras como "La Niña de los Lirios", plenamente simbolista, o "La Gitana", influido claramente por la "Olimpia" de Manet, que sin duda tuvo ocasión de contemplar.

A partir de este momento, los retratos de la sociedad madrileña y sevillana, y los de caza y venatoria, le proporcionaron un gran éxito social y económico. En 1923 compró la casa con un hermoso jardín (Fig. 1) donde, tras muchas transformaciones, sigue ubicándose actualmente la Fundación Manuel Benedito evocando al primer inmueble. En 1924 ingresó como académico numerario de la Real Academia de Bellas Artes de San Fernando, ocupando en 1925 el sillón de Sorolla de la Hispanic Society y, además, ejerció como profesor de Color de la Escuela de Bellas Artes. Manuel Benedito, tras una vida de éxito como pintor, muere en 1963. Al no casarse ni tener descendencia, adoptó a su sobrina Vicenta Benedito, quien se convirtió en heredera de su legado.

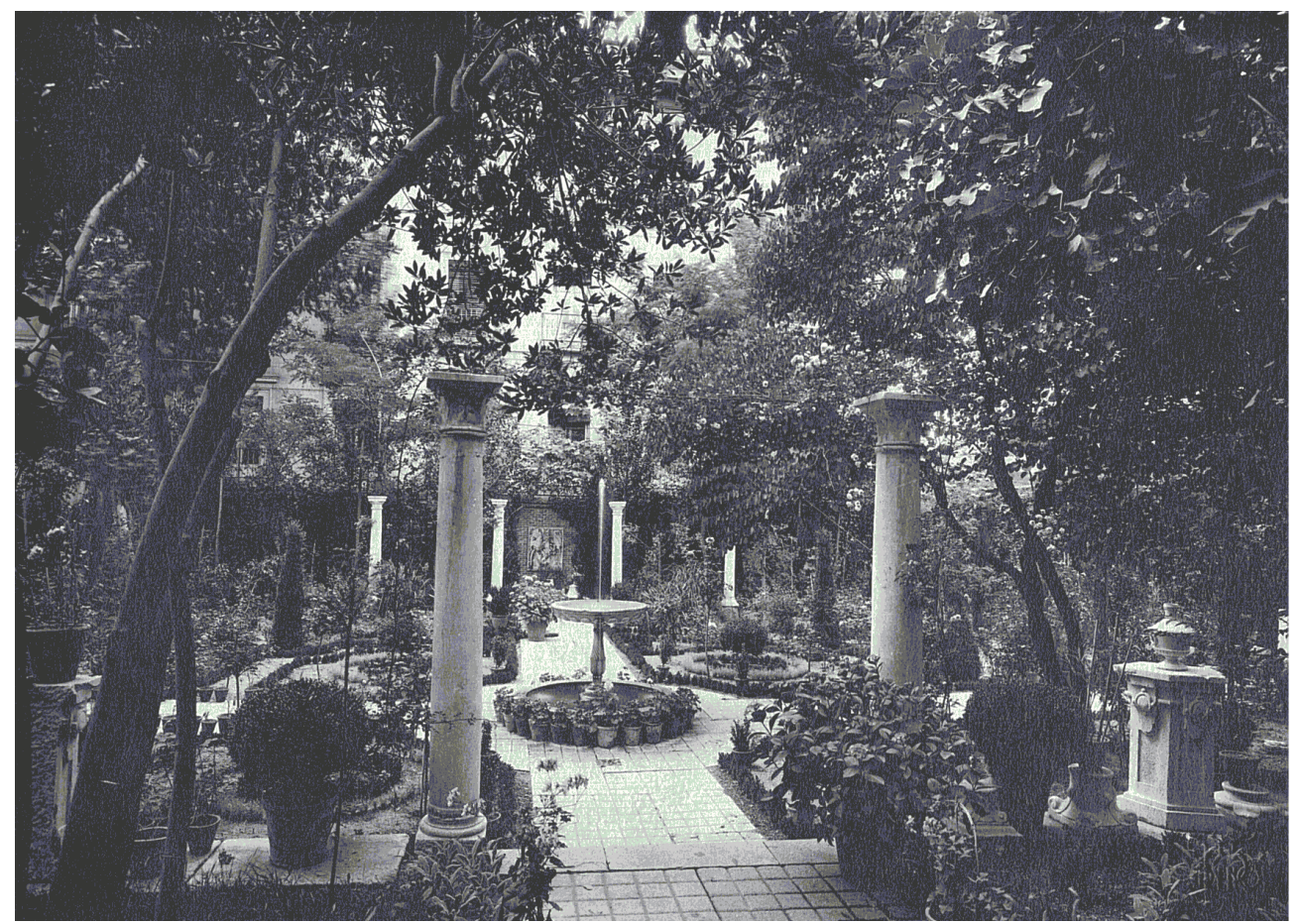

Fig. 1. Jardín original de la casa de pintor. 


\section{La fundación Manuel Benedito: Una institución desconocida para el público}

La fundación Manuel Benedito fue creada en

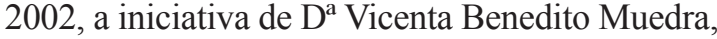
sobrina adoptada por el pintor. Se encuentra ubicada en el mismo lugar de la madrileña calle de Juan Bravo 4, dónde el pintor tuvo, desde 1927, su casa y su estudio (Fig. 2). Al fallecimiento de éste, la sobrina y ahijada del pintor se convierte en garante del legado de su tío, custodiándolo hasta 2008 en que fallece. Durante los años transcurridos desde la muerte de su tío hasta su propio deceso, la sobrina vendió el solar donde se ubicaba la casa y se levantó el edificio actual de varios pisos. Dispuso las indicaciones precisas para que se construyera, en la planta baja, un local que "reprodujera" en dimensiones y altura el estudio del pintor, con la finalidad de que las obras que heredó de su tío pudieran ser expuestas al público. Y así se venía haciendo cada vez que se le solicitaba. Siendo ya longeva y preocupada por el destino de dicho legado a su muerte, $\mathrm{D}^{\mathrm{a}}$ Vicenta Benedito, con el asesoramiento jurídico oportuno, decide crear una fundación para asegurar, cuando ella no esté, el mantenimiento y la difusión del legado recibido.

Al fallecer la heredera, dado que ya estaba constituida la fundación, el patronato de la mis- ma, designado íntegramente por ella, estaba formado por personas de su entera confianza como familiares muy cercanos y otras personalidades que se hacen cargo de la gestión y dirección de la misma, decidiendo dar un cambio a su funcionamiento. En 2009, el patronato se propone acometer una obra de transformación del espacio, adecuándolo museográficamente para exponer dignamente la colección. Para ello, se incorporan nuevas instalaciones eléctricas y nuevos paramentos, así como la supresión de otros dándole, en general, un aire más contemporáneo. La colección se muestra en un espacio híbrido entre lo que se denomina casa-museo o museo de autor y lo que se considera colección visitable, que no llega a ser un museo en el sentido estricto del término. Este intento de musealización y su resultado es lo que intentamos mostrar en este artículo.

Tras la rehabilitación física del inmueble y una ligera puesta al día museográfica, el patronato decide que la fundación sólo tiene sentido si es visitable por el público, pues de lo contrario estaba abocada a una lánguida desaparición por inactividad y por no cumplir su cometido. Para ello, se necesitaba un especialista encargado exclusivamente de la institución y que desarrollase las funciones directivas de la misma, siendo yo misma seleccionada para acometer dicha tarea. A

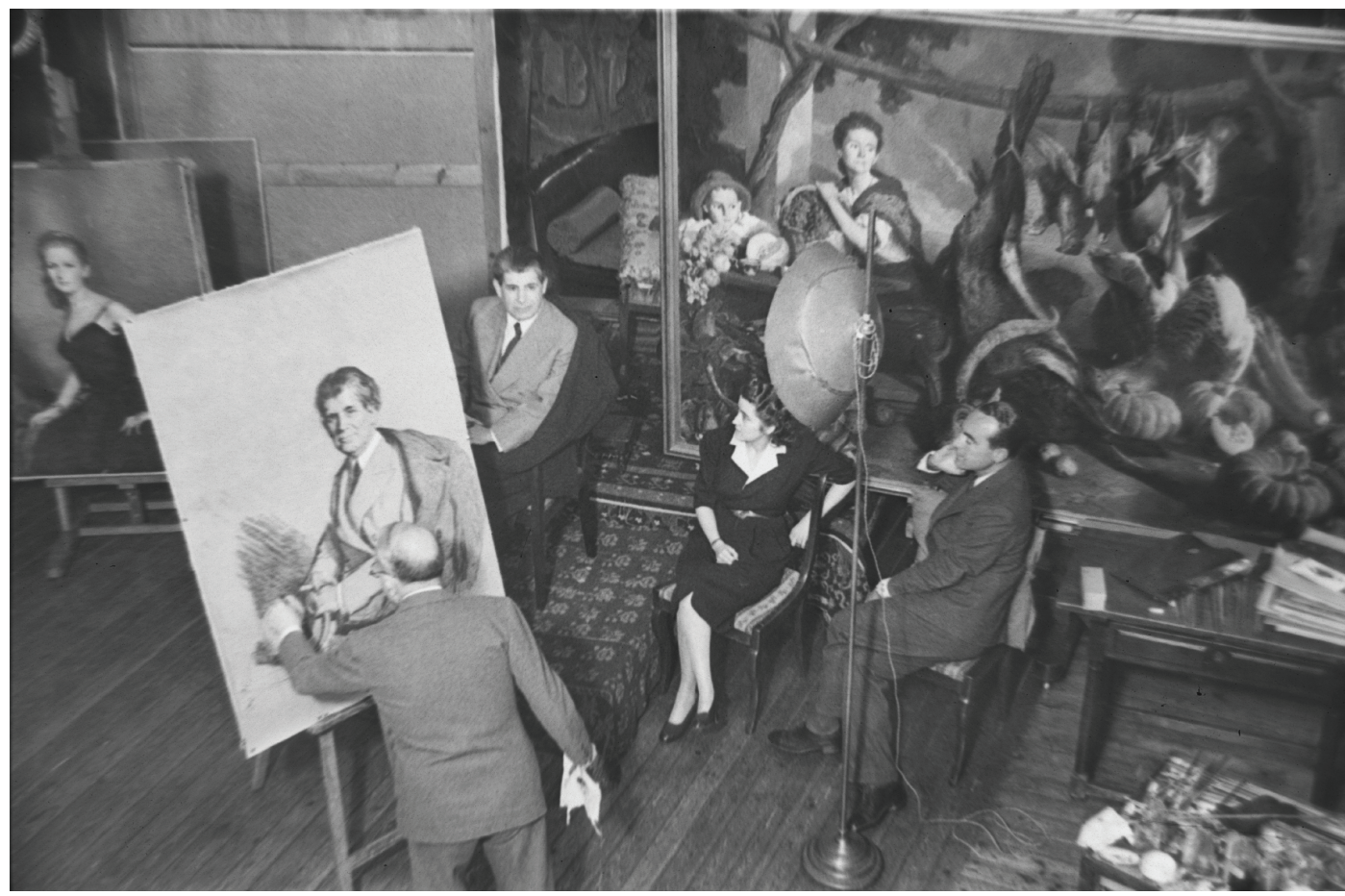

Fig. 2. Manuel Benedito pintando en su estudio. 
partir de entonces, la gestión seguirá siendo privada, teniendo como objetivo dar a conocer la colección de pintura al público en general mediante citas concertadas y visitas guiadas por voluntarios o por guías privados especializados.

\section{La fundación: Entre museo de autor y casa museo}

La Fundación Manuel Benedito dedica sus salas básicamente a exponer la obra del pintor. Se ha intentado reproducir, en la medida de lo posible, el ambiente donde el pintor creaba sus obras. La heredera acordó con el arquitecto Zuazo, uno de los más prestigiosos del Madrid de la época, que se reprodujera en el nuevo edificio, construido sobre la vivienda-taller de Manuel Benedito, un local en la planta baja de las mismas dimensiones que la original, con doble planta y acceso directo desde la calle, para que recordase el estudio del pintor. Sin embargo, este local carece de algo fundamental que sí tuvo el estudio verdadero del pintor: luz natural cenital (Lafuente Ferrari 1976: 7 y ss.). De ahí que, aunque la fundación quiera reproducir el ambiente de aquel estudio, la ausencia de luz natural marca unas claras diferencias con lo que fue el lugar de trabajo original del pintor, donde consideraba imprescindible la iluminación natural a la hora de realizar sus obras. Sin embargo, en la actualidad este espacio solo cuenta con iluminación artificial y es uno de los grandes condicionantes a la hora de realizar la visita (VVAA 2005:15-30).

Además de la exposición pictórica de la obra que la fundación conserva del pintor, se ha seguido manteniendo parte del mobiliario que tenían el pintor y su sobrina en el antiguo caserón y que, en muchos casos, Manuel Benedito compró a anticuarios: colección de baúles datados entre los siglos XVII y XIX, mesas estilo Felipe V, jamugas, mesas castellanas de fiadores, columnas romanas que antes adornaban el jardín, una lámpara de cristal de la Real Fábrica de Cristal de la Granja del XVIII, una balaustrada confeccionada a partir de secciones de un artesonado religioso $\mathrm{y}$ unas puertas de bronce estilo renacimiento, así como paletas, pinceles, maletines y tubos de pigmentos que formaban parte de los enseres del pintor. Todo ello con la única finalidad de evocar la vida de Manuel Benedito en su espacio doméstico.

El éxito reciente que actualmente tiene la exposición permanente de la fundación reside, en gran parte, en esa mezcla de museo dedicado a un autor y su obra, y también al ambiente reproducido de su casa-estudio, que ayuda a un mejor conocimiento de la vida y obra del artista. Así, en las visitas guiadas siempre se intenta destacar que no se trata del espacio original, sino que se ha intentado recrear el ambiente de la época, algo que merece los elogios de los visitantes y que le imprime un carácter específico, diferenciándolo de otros donde se muestra la obra de un artista dentro de un espacio totalmente neutro o en su contexto original.

Las casas-museo cuentan con una larga historia y, en épocas más recientes, su desarrollo ha seguido el mismo que la de todos los museos. En los últimos años del siglo XX se ha dado el fenómeno, calificado como "museomania", con la aparición de una gran diversidad de instituciones de temática y características muy diferentes. Es dentro de este contexto cuando en España comienzan a proliferar los museos de autor o biográficos, centrados en la obra artística, literaria o científica de una reconocida persona en el campo artístico, literario, científico o de cualquier otra actividad que haya influido en el ambiente de su época. Museos como Ulpiano Checa, Chillida Leku y Balenciaga, o casas-museo, entre las que pueden citarse las de Miró o Picasso entre otras (Velasco 2013). Fenómeno que se da en otros países, entre las que se encuentran la casa-museo de Guayasamín en Quito o el Barnes Museum de Filadelfia o la Frick Museum de Nueva York. Si bien estos museos nacen con el afán de comunicar, difundir y preservar la obra de un autor, muchos de ellos fracasan en el tiempo, que no en el intento, dados los costes inasumibles que tiene una entidad abierta al público y con vocación de servirle (Benítez Silva 2014).

Normalmente, los museos de autor y las casasmuseo tienen tras de sí una fundación garante de la obra que se exhibe y de su continente. El mantenimiento de ambos, por mucha dotación, herencia o legado que tenga la fundación, es inasumible si no hay unos ingresos o un flujo de aportaciones abundante. El personal, la seguridad, el mantenimiento de la obra y el edificio, el diseño de la web y el mantenimiento o las visitas virtuales tienen tales costes que normalmente, tras un período de apertura, dichas instituciones se ven abocadas al cierre y, en el peor de los casos a su desaparición, a pesar de que el artista sea reconocido internacionalmente y de que nadie cuestione la valía de la obra y del museo, como sucede con el Chillida Leku (Landa López 2010). 


\section{La comunicación como objetivo prioritario}

Desde el comienzo se tuvo conciencia de que una de las labores prioritarias era comunicar y difundir el nombre de la fundación y de su contenido. La dificultad estaba en cómo realizar esto cuando prácticamente el personaje había sido olvidado en el tiempo (Laporte 2013: 26). Como el nombre y el logo ya habían sido elegidos en el 2002 por la creadora de la fundación, se decidió mantenerlo. También se anuncia en la puerta de cristal de entrada un vinilo de corte con el nombre y teléfono de la institución, que la visita se ha de realizar previa cita concertada, y figura la web donde se puede consultar más información. Esta puerta de cristal forma parte de la nueva reforma y sustituyó a la original de bronce que se introdujo al interior para preservarla de agresiones externas, como la contaminación, el vandalismo o el robo. Este cambio proporcionó un "escaparate" a la calle, puesto que desde el exterior se pueden percibir algunas de las obras y de los enseres del pintor. Del mismo modo, se realizó el diseño de una página web muy sencilla con información general sobre la situación, accesibilidad, transporte, precios y mapa de ubicación, una visita virtual con $360^{\circ}$ de movimiento, una pequeña sinopsis de la vida y obra del pintor y, por último, la composición del patronato.

La página web ha tenido muchísimo éxito y las visitas se han ido incrementando con el tiempo (www.fundacionmanuelbenedito.com). Lo más importante de este portal es que los visitantes potenciales, locales o foráneos, se animan o se sienten atraídos por lo que muestra la visita virtual, llegando a ser una opción más para visitantes extranjeros de Italia, Francia o Estados Unidos, que se acercan a Madrid atraídos por la oferta cultural de la ciudad y la singularidad de estas instituciones.

Además, en consonancia con los nuevos tiempos, la web tiene enlace con los recursos de la web 2.0 -Twitter y Facebook-, donde la fundación publica aspectos de su actividad diaria como exposiciones temporales, préstamos de obras a otras exposiciones, visitas ilustres, remates en subasta, etc. El link con la fundación está disponible desde la base de datos de la Guía de Turismo del Ayuntamiento de Madrid, de la Comunidad de Madrid y desde la Base de Datos de Colecciones Visitables del Ministerio de Educación y Cultura. El soporte clásico de la comunicación es el folleto explicativo que se les da a los visitantes. Se trata de un tríptico, con un texto muy sinté- tico sobre el pintor, su obra, y la fundación que incluye una elevada cantidad de imágenes de los cuadros y, en la contraportada figuran los datos esenciales de interés para el visitante: dirección, teléfono, web y correo electrónico de contacto. Desde su apertura, se ha ido renovando y actualizándolo, haciéndolo más atractivo. Hemos de resaltar que la recomendación personal ha sido el elemento más importante para dar a conocer la institución. Los visitantes que vienen recomendados por otras personas suelen salir muy satisfechos y repiten la visita siempre que les sea posible, lo que supone un motivo de satisfacción.

Uno de los objetivos principales fue programar las líneas básicas para una correcta y eficaz difusión. Por ello, se comenzó a contactar con instituciones dónde se pudieran realizar exposiciones temporales con la obra del autor, con periodistas que estuvieran interesados en realizar reportajes de la fundación y se facilitó información a toda persona interesada en mencionar o hablar de la fundación en cualquier medio. En 2013 se organizó una exposición temporal para conmemorar el 50 aniversario del fallecimiento del pintor. La sede donde tuvo lugar dicha muestra fue la Sala de Exposiciones Temporales de la Real Academia de San Fernando de Madrid, dado que Manuel Benedito fue Académico Numerario de la misma y Presidente de la Comisión de Calcografía. Se exhibieron un total de 68 obras.

Para dicho acontecimiento se editó un pequeño catálogo conmemorativo (Masíá González 2013), en donde figuran todas las obras pertenecientes a la fundación y las que fueron solicitadas en préstamo a otras instituciones, como la colección Carmen Thyssen, Museo del Prado, Casa de Alba y Real Academia de San Fernando. El texto del catálogo analiza con precisión cuál fue el contexto en el que Manuel Benedito fue designado Académico Numerario y qué supuso para él su desempeño.

Para la Fundación significó una apuesta muy importante, tanto desde el punto de vista económico como de prestigio de la institución, puesto que tuvo una gran repercusión mediática. Para la difusión y comunicación de la exposición temporal, se decidió contar con los servicios de una empresa de comunicación que ya tuviera alguna experiencia en el mundo del arte. Entre las conocidas, se eligió a Global Design, quien durante un mes y medio mantuvo las redes sociales de Twitter y Facebook, organizando la rueda de prensa y el mailing para la inauguración. A la misma asistieron unas 300 personas, número muy elevado 
para este tipo de acontecimientos. Se realizó una campaña de difusión a través anuncios en la prensa nacional, provincial y local. Esto contribuyó a que durante cinco semanas se acercaran a la exposición unos 10.800 visitantes, contribuyendo a dar a conocer la Fundación (Informe de Público facilitado por Magma Cultura).

El resultado fue muy positivo, puesto que la noticia apareció en prensa, radio y televisión y se consiguió que también saliera algún reportaje más sobre la fundación en otros medios especializados en arte, como la Revista Descubrir el Arte (Sanz Coca 2014: 90-92). También la Fundación Maxam (2014) ha dedicado un artículo sobre Manuel Benedito en la Revista Shaping. Además, han salido artículos mencionando al pintor Manuel Benedito o a la fundación en Expansión, $\mathrm{ABC}$ y El Mundo. Con respecto a otros medios, se realizó un reportaje para la televisión valenciana Mundo.TV con gran repercusión en el incremento de las visitas y tuvimos la fortuna de que saliera la exposición cerrando el telediario regional de Madrid el día 24 de septiembre de 2013.

\section{El discurso expositivo}

Desde que la fundación Manuel Benedito reabrió al público, el 6 de abril de 2011, hubo que elaborar un discurso para el público visitante. Dicho discurso no podía centrarse únicamente en la obra del pintor. Por eso, como bien expresa Antoni Laporte (2013: 23), se ha realizado un esquema en el que, siendo la evolución pictórica la columna vertebral del discurso, este se articula a través de su ciclo vital, su vida doméstica y los temas universales que son susceptibles de captar la atención del oyente: amores, amistades, odios, genialidades, etc. De este modo, se presenta al artista, al hombre, al hijo, al tío y se le da un enfoque muy activo.

De hecho, la presentación del pintor y de la fundación se realiza en el propio hall de entrada, donde se encuentra el óleo sobre lienzo "El jardín", en donde él representó el jardín de su casa, el pórtico interior y las columnas romanas que aún se conservan, y en donde también se muestra al pintor en un autorretrato. Así, por un lado, se presenta al pintor y se dan las pinceladas clave del nacimiento y del fallecimiento, al tiempo que se le ubica en Madrid, donde desarrolló una dilatadísima vida como artista.

El discurso ha tenido que adaptarse al espacio expositivo de que se disponía. El criterio de la exposición permanente, que ha experimentado pocos cambios a lo largo de estos dos años, puede considerarse temático-cronológico, aunque en alguna ocasión han prevalecido las dimensiones de las obras que requieren un espacio mayor, como ocurre con el boceto del "Canto VII Infierno de Dante", cuyas medidas son $380 \mathrm{~cm}$ x $150 \mathrm{~cm}$.

Este criterio ha llevado a disponer las obras de forma coherente, tratando de resaltar su valor estético. De hecho, la única posibilidad de apreciarlas es a través de una visita guiada, que pueda transmitir un discurso lógico de toda la exposición. Efectivamente, se puede criticar que este criterio no sea el correcto, pero se ha preferido que el visitante, después del recorrido de las salas, salga con una visión amplia de la vida del pintor, de su obra y de todo el contexto social y cultural en el que tuvo lugar. Podría discutirse la idoneidad o no de disponer de cartelas identificativas en cada una de las obras, donde figure el título, año, tamaño y técnica. Sin embargo, conociendo las últimas tendencias que promueven la supresión de las mismas, se ha apostado por la visión directa de la obra sin interferencias de ningún tipo. Para ello, se presenta un discurso explicativo que lleve al público a valorar positivamente la exposición. Hemos de resaltar que, al menos un 5\% del público, opina que sí deberían colocarse dichas cartelas. Además de las visitas guiadas, se ofrece, para una mayor información del público, un folleto explicativo de la vida del pintor y su obra, que ha tenido una gran aceptación.

A la hora de detectar los problemas surgidos en el montaje de la exposición, hemos observado que uno de ellos está relacionado con la iluminación, dado que, si ésta es excesiva, hay muchos cuadros que tienen reflejos producidos por el barniz o por los cristales. Se observa que en algunos de los cuadros no se perciben bien los valores técnicos y estéticos, puesto que el pintor realizó los cuadros para ser vistos con luz natural y aquí son expuestos en un espacio ciego que necesita de la luz artificial. Como discípulo de Sorolla, mantiene la idea de que sus obras han de ser contempladas a la luz del día. Tras dos años de apertura de la sede renovada, se ha ido modificando poco a poco la iluminación con muchas dificultades y con un coste muy elevado.

La sala de exposición trata de evocar lo que fue la casa y el estudio del pintor y, para ello, se ha intentado acondicionar con algunos muebles de época y diversos instrumentos que utilizó en sus creaciones (Fig. 3). Al variar las dimensiones 


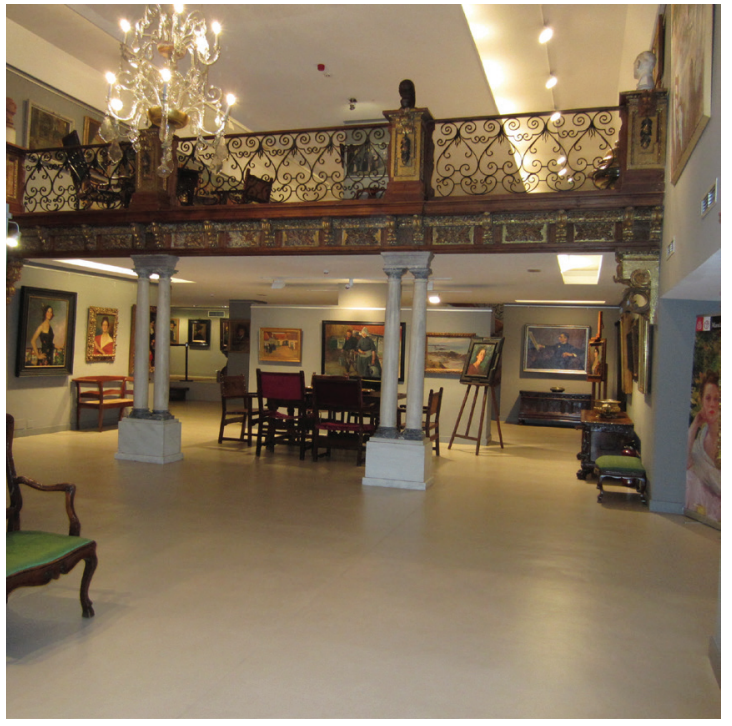

Fig. 3. Vista general de la sala de exposición.

de los espacios, se ha procurado reducir la visita a grupos de 20 personas como máximo. Con ello se pretende facilitar el itinerario y la contemplación de las obras, así como velar por su seguridad. En un primer momento, había más mobiliario expuesto de la casa del pintor y de la heredera. Pero, tras el nuevo planteamiento, con una vocación mucho más pública que antes, y a fin de que el recorrido estuviera lo más diáfano posible, se decidió exponer el mobiliario, compuesto por arcas de novia, jamugas, baúles, fraileros, papeleras y mesas, más pegado a las paredes. Sin embargo, no se muestra la inmensa colección de objetos de artes decorativas, sobre todo cerámicas de Talavera y de reflejo dorado o Manises y vasijas de bronce y latón. Esto fue motivado por el grave peligro que suponía tener dichas cerámicas expuestas. Actualmente, sólo se exhiben cuatro cerámicas de este tipo en unas vitrinas (Fig. 4).

El intento de dar a conocer la labor que realiza la Fundación nos ha llevado a elaborar un folleto que se ofrece a la entrada, así como a fomentar el diálogo con los visitantes durante las visitas guiadas. De hecho, hemos recibido muchas felicitaciones por este motivo. En este punto es cierto que una visita guiada puede ser una visita excepcional (Laporta 2013: 24), y que ayude a comprender mejor la exposición, siempre que se cuente con personal preparado para ello. Hemos de elaborar "discursos a la medida" e ir subiendo el nivel o bajándolo según vemos las reacciones del público. Esta tarea la lleva a cabo la institu-

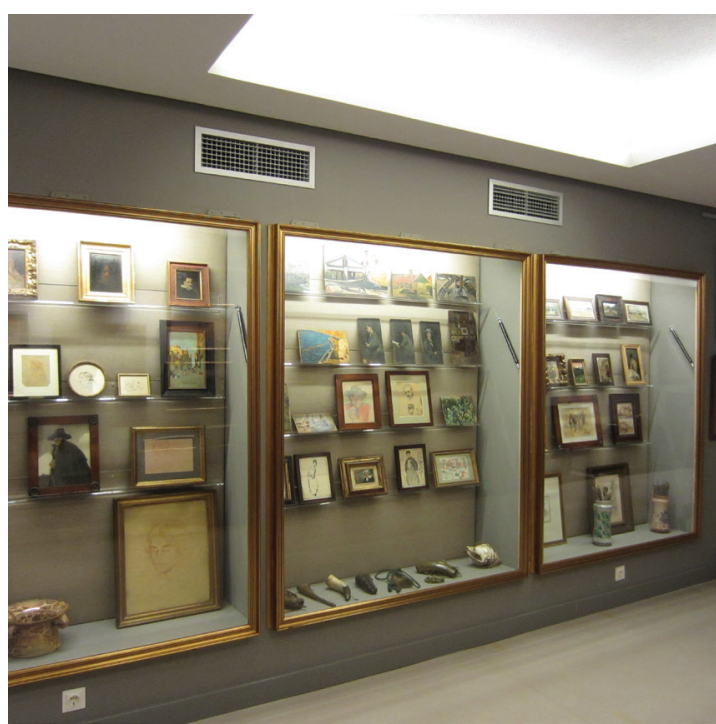

Fig. 4. Vitrinas con cuadros y objetos del pintor.

ción de una manera continuada. El hecho de que la mayoría de los grupos salgan muy satisfechos, es un signo de que el discurso ha llegado, se ha entendido y, lo más importante, que ha gustado.

Por ello, es fundamental saber de antemano, a través de los responsables de los grupos o asociaciones, qué tipo de personas vamos a recibir para ofrecerles una acogida cálida y adecuada. La fundación colabora con un programa de acercamiento de los museos a la Tercera Edad. Cuando recibimos a estos grupos, les ponemos todas las facilidades simplificando el discurso, vamos preguntando si se encuentran cansados, si lo entienden $\mathrm{y}$, además, procuramos que las visitas sean distanciadas de manera que no coincidan al mismo tiempo varios grupos que puedan, de algún modo, incomodarles.

\section{La financiación de las pequeñas colecciones y la Ley de Mecenazgo (49/2002)}

La institución, tras dos años de mucha actividad y de no escatimar gastos, ha llegado al límite en el que por sí sola y sus presupuestos económicos no puede desarrollar plenamente sus objetivos. Son tales los gastos que una institución de este tipo soporta, que en este momento es necesaria la búsqueda de una financiación externa.

Desde hace tiempo se viene aplicando la autofinanciación, pero a corto plazo este planteamiento no ha resultado viable dado que, tan sólo 
a través de los ingresos por entradas y venta de catálogos, no se ha logrado financiar ni siquiera un 5\% de los gastos de la fundación. El planteamiento de subir el precio de las entradas no sería apropiado porque conseguiríamos el efecto "rebote" al salirnos del precio de "mercado" y quedaría como una institución elitista dirigida a grupos con alto poder adquisitivo. Por otro lado, la venta de catálogos no es tan fluida como podría pensarse, por lo que los ingresos procedentes de esta venta son muy escasos.

Otra de las opciones es aumentar el número de visitas puesto que, al ser la institución de tamaño pequeño, sólo se admite un grupo de visitantes por cada hora. Para poder llegar a tener dos grupos simultáneos sería necesario incrementar la plantilla, al menos, en una persona. Por otra parte, si hubiera entrada libre sin citas también debería incrementarse el personal de vigilancia en puerta y salas. Como podemos apreciar, cualquier intento de incrementar el flujo de público, implica, obligatoriamente, un aumento de personal y, con ello, de presupuesto.

Al hablar de la financiación externa hemos de tener en cuenta que se trata de una institución poco conocida y que su capacidad de promoción es mediana. Esto conlleva que las entidades que financian mediante el patrocinio o mecenazgo a instituciones o actividades culturales, no se planteen hacerlo con una institución de estas características, debido al poco impacto mediático que tiene. Esto es debido a que el rédito del patrocinio está basado sobre todo en la publicidad y en la buena imagen que les da fomentar las actividades culturales, educativas, o sociales, y no tanto en lo que puedan desgravarse en Hacienda. La actual Ley 49/2002, de 23 de diciembre, de régimen fiscal de las entidades sin fines lucrativos y de los incentivos fiscales al mecenazgo, conocida como Ley de Mecenazgo en el gremio de los museos y colecciones, no es el mejor marco jurídico para estimular esta actividad. Para las pequeñas instituciones como esta, es casi una quimera encontrar un gran patrocinador a quien solo le interesa la publicidad en marquesinas, banderolas y anuncios de prensa y televisión. Con esta situación, la búsqueda de un pequeño patrocinador en el actual estado de crisis económica es, realmente, muy difícil. Confío en que la futura modificación de la Ley de Mecenazgo, tan necesaria para el fomento de la cultura española, sea una ley no sólo que "incentive" de verdad, sino que estimule a las pequeñas, medianas, y grandes empresas a este tipo de actividades que, por otra parte están ya muy implantadas en países anglosajones o del Norte de Europa (Raposo 2014: 11-12).

A pesar de esto, no podemos dejar de ver que el problema de la financiación de los museos y de las colecciones es propio de estas instituciones, por mucho que su actividad repercuta en la sociedad. Dentro de este contexto de crisis económica mundial, en donde los recortes en los museos incluyen reducción de personal, de presupuestos y de infraestructuras, resulta difícil ver un futuro claro para este tipo de instituciones (Raposo 2014: 10). Sin embargo, paradójicamente los museos y colecciones alcanzan cada vez un porcentaje más elevado en el PIB de muchos países como Reino Unido (2.000 millones de libras), EE.UU. (21.000 millones de dólares), inaugurándose cada vez más instituciones (sólo China abrió en 2012 quinientos museos nuevos) (Raposo, 2014: 11). Esta crisis ha generado una serie de estrategias, tanto de diversidad en los museos como de su financiación. Son estas estrategias las que debemos analizar para saber si tenemos una "cuota de mercado", o si el tipo de museo que se gestiona tiene cabida en la demanda, y adaptar la institución a ésta para generar ingresos. Sólo esta medida, que puede ser tildada de excesivamente económicista, puede salvar a las instituciones pequeñas de nuestro perfil.

\section{Conclusiones}

Dentro de los museos de autor se pueden diferenciar distintos tipos según las características propias de cada uno de ellos. Ciertamente, todos los museos de autor no son el Museo Sorolla ni, por supuesto, tienen 173.000 visitas anuales (Velasco 2013). Existen tres condicionantes que explican el interés que despierta dicho museo. Una de ellas es el reclamo de la figura del propio artista, de su pintura con esa luz mediterránea tan característica, y la plasmación de temas tratados con delicadeza y amabilidad. Otra consiste en el hecho de que su titularidad sea estatal desde 1932, pasando por altibajos aunque siempre con el respaldo económico del Estado. Finalmente, el hecho de ser también una casa-museo, posee el encanto de entrar a ese jardín en medio de la ciudad y que Sorolla tantas veces pintó, así como adentrarse en la vivienda subiendo las escaleras que él y Clotilde utilizaban, o admirando las arañas que gustaban a sus hijos. Esa emoción es única.

Aunque todos los museos pueden considerarse dentro de la catalogación "de autor" y también 
algunos como "Casa-museo", podemos afirmar que la Fundación Manuel Benedito pertenece a los museos de autor y que, en ningún caso, puede considerarse casa-museo al haberse perdido el contexto original en el que vivió el autor. Deberíamos hablar, más bien, de una recreación o evocación de lo que pudo ser la vivienda del artista.

Uno de los grandes problemas que tienen esta clase de museos es el de la financiación. En la mayoría de los casos, los museos de autor o casas-museo se financian con fondos propios. Unas veces legados por los propios autores o coleccionistas, otras producidos por los mismos, como sucede con la Fundación Tapies que genera ingresos para su propia subsistencia o el Museo Dalí de Figueras, que consigue incluso excedentes, y finalmente aquellos que cuentan con patrocinio externo y que son casos bastante infrecuentes (Landa López 2010:1).

Podemos preguntarnos sobre si es o no conveniente que se creen estos museos, pero lo cierto es que hoy día contamos con un gran número de ellos de temática y características muy diversas. Eso significa que debemos potenciarlos porque son museos especializados, de mediano o pequeño tamaño, que nos transmiten vivencias de los personajes que habitaron estos espacios y que, por ese motivo, resultan muy atractivos y nos muestran diferentes maneras de contemplar el patrimonio cultural. Sobre el futuro de estos museos, hemos de resaltar que uno de los factores determinantes será el económico. Por ese motivo, todos aquellos museos que cuenten con fondos propios y sean apoyados por diversos organismos públicos, ya sean estos locales, comunitarios o estatales, podrán salir adelante y tendrán un futuro prometedor. Sin embargo, los que no logren conseguir estas ayudas tendrán serios problemas para subsistir en condiciones de poder ofrecer todos los servicios que el público les reclame. No obstante, hemos de ser conscientes de que ni lo público puede sustentar todas las colecciones, ni muchos museos estarán dispuestos a cerrar sus puertas a pesar de no tener el éxito de público deseado.

Finalmente, hemos de señalar que, nuestra experiencia al buscar patrocinio para la exposición temporal durante el 2013 en la Sala de exposiciones temporales de la Academia de Bellas Artes de San Fernando, fue negativa, tal vez porque la Fundación era poco conocida por los potenciales patrocinadores. Después de la exposición, sufragada íntegramente con fondos propios, esperamos resulte más fácil conseguir algún patrocinio para potenciar las actividades que venimos realizando o para iniciar otras nuevas. La experiencia de otras fundaciones nos demuestra que, en estos momentos, es muy difícil conseguir un patrocinio o mecenazgo para este tipo de proyectos culturales. Ahora mismo lo que está funcionando mejor es el micromecenazgo. Este consiste en pequeñas aportaciones de capital de diferentes empresas que, junto a otras cantidades, y a cambio de publicidad, consiguen poner en marcha dichos proyectos. En estos momentos, contamos con una propuesta atractiva, como un patrocinio parcial para el mantenimiento de la web a través de la publicidad de una empresa, mediante un banner en el inicio de la misma. Además, tenemos disponibles los espacios de la fundación para su alquiler, al igual que hacen otras fundaciones de nuestro entorno, como la Fundación Carlos de Amberes o la Fundación Lázaro Galdiano. Mientras tanto, la Fundación seguirá trabajando con ilusión y constancia con el fin de conservar y difundir la obra de Manuel Bendito, de manera que pueda ser conocida por las nuevas generaciones.

\section{REFERENCIAS BibLIOGRÁFicas}

Benítez Silva, E. (2014): Reportaje Museos de Autor: De Chile para Chile. [URL: http://www.arteallimite. $\mathrm{com} /$ periodico/reportaje-museos-de-autor-de-chile-para-chile-2-3]. Acceso el 04/09/2014.

Fundación MAXAm (2014): Manuel Benedito. El Académico Virtuoso. Revista Shaping, nº 22: 20-23. [URL: http://es.slideshare.net/WalterCardenas1/revista-shaping-22]. Acceso el 17/10/2014.

Lafuente Ferrari, E. (1976): Manuel Benedito. 1875-1963. Catálogo de la Exposición conmemorativa del centenario del pintor. Madrid.

LANDA LóPez, I. (2010): ¿Cabe tanto museo de autor? [URL: http://elpais.com/diario/2010/12/04/sociedad/1291417201_850215.html]. Acceso el 22/9/2014.

LAPORTE, A. (2013): Estructuración, comercialización y comunicación de casas museo como productos de turismo cultural. Casas museo: Museología y Gestión. Actas de los Congresos sobre Casas Museo (2006, 2007, 2008). Ministerio de Educación, Cultura y Deporte, Madrid: 22-27. 
Manaut Viglietti, J. (1958): La Personalidad de Manuel Benedito. Revista Goya, nº 26: 127-130.

Masiá González, P. (2013): Manuel Benedito en la Academia. Fundación Manuel Benedito. Valencia.

Poole, N. (2014): En la Encrucijada. Museos, crisis y finanzas. Las Noticias del ICOM, nº3: 12-13.

RApOSo, L. (2014): En la encrucijada. Museos, crisis y finanzas. Las Noticias del ICOM, nº3: 10-11.

SAnz CocA, A. (2014): Fundación Manuel Benedito. Amor por la pintura. Revista Descubrir el Arte. № 179: 90-92.

VV.AA. (2005): Manuel Benedito, pintor (1875-1963). Generalitat Valenciana. Valencia.

VV.AA. (1910): Maestros jóvenes: Manuel Benedito. Europa, Revista de Cultura Popular, Año I, nº 5: 6870.

Velasco, C. (2013): Museos de autor, una fórmula de éxito. [URL:http://www.lasprovincias.es/20131118/ mas-actualidad/cultura/museo-autor-201311180252.html]. Acceso el 8/09/2014. 